\title{
Composition and characteristics of distinct macrophage subpopulations in the mouse thymus
}

\author{
LAN-TAO LIU ${ }^{1,2}$, ZHI-FANG LANG ${ }^{2}$, YING LI ${ }^{1}$, YONG-JIE ZHU ${ }^{1}$, JIU-TAO ZHANG ${ }^{2}$, SHANG-FU GUO ${ }^{2}$, \\ JI-XI WANG ${ }^{1}$, HONG-WEI WANG ${ }^{2}$ and YU-DONG XU ${ }^{1}$ \\ ${ }^{1}$ Department of Anatomy, Harbin Medical University, Harbin, Heilongjiang 150086; \\ ${ }^{2}$ Mudanjiang Medical College, Mudanjiang, Heilongjiang 157011, P.R. China
}

Received December 7, 2012; Accepted April 23, 2013

DOI: $10.3892 / \mathrm{mmr} .2013 .1448$

\begin{abstract}
The aim of the present study was to investigate the composition, morphology, characteristics, distribution and function of distinct macrophage subpopulations in the mouse thymus. Apoptosis of mouse thymocytes was induced by glucocorticoids and three monoclonal antibodies against Mac-2, F4/80 and ED1 were used for immunofluorescence staining and immunohistochemical analysis. The morphology of thymic macrophages was examined by transmission electron microscopy. Four subpopulations of mouse thymic macrophages were identified. Dendritic macrophages were identified using anti-Mac-2 and anti-F4/80 antibodies, and were demonstrated to be distributed in the entire thymus. Phagocytes were also observed. In addition, plate-shaped macrophages, identified using the anti-F4/80 antibody, were distributed under the thymic cortex capsule. Small oval macrophages, identified using the anti-Mac-2 antibody, were distributed in the thymic medulla and corticomedullary region $(\mathrm{CMR})$, while phagocytes were not observed in these types of cell. ED1 ${ }^{+}$thymic macrophages with irregular forms were distributed in the CMR. All of the four subpopulations of mouse thymic macrophages described above exhibited acid phosphate activity. This study indicated the existence of macrophage subpopulations with different shapes, distribution and functions in the mouse thymus.
\end{abstract}

\section{Introduction}

The thymus is one of the central organs of the immune system where $\mathrm{T}$ cells develop, differentiate and mature. In recent years, it has been demonstrated that stromal cells of the thymus are important in the differentiation and selection of thymic

Correspondence to: Professor Yu-Dong Xu, Department of Anatomy, Harbin Medical University, Harbin, Heilongjiang 150086, P.R. China

E-mail: xuyudong11@163.com

Key words: thymus, macrophage, subpopulation, monoclonal antibody lymphocytes. Macrophages are a type of thymic stromal cell that are involved in phagocytosis and antigen presentation $(1,2)$. Additionally, macrophages secrete cytokines, which may affect thymocyte proliferation, maturation, differentiation and the negative selection of potential self-reactive T-cell clones $(3,4)$. Furthermore, macrophages are important in immune reactions, particularly tumor immunity (5).

Previous studies have shown that macrophages are generally heterogeneous in their phenotype and function (6). Immunohistochemical examination in rats employing ED1, ED2 and ED3 monoclonal antibodies (mAbs) has demonstrated that there are distinct subpopulations of thymic macrophages (7). Compared with rat thymic macrophages, fewer studies have focused on the macrophages of the mouse thymus. To understand the characteristics of these cells, we examined mouse thymic macrophages by immunofluorescence staining, immunochemistry and acid phosphatase (ACP) activity double staining using various mAbs.

\section{Materials and methods}

Animals. Female BALB/c mice (4-6 weeks old) were obtained from the Experimental Animal Center of Harbin Medical University (Harbin, Heilongjiang, China). All of the animal experiments performed were reviewed by the Ethics Committee for Animal Experiments at Harbin University School of Medicine and every procedure followed the Guidelines for the Care and Use of Laboratory Animals.

Antibodies. Affinity purified anti-mouse F4/80 antibody, rabbit anti-CD68 (ED1), FITC-labeled goat anti-rat IgG and goat anti-rabbit IgG/RBITC were purchased from BD Biosciences (Franklin Lakes, NJ, USA). The antibody against LGALS3Bp (Mac-2) and biotin-SP-conjugated affinity purified donkey anti-rabbit IgG were purchased from PTGLabs (Chicago, IL, USA). ExtrAvidin-Cy3 conjugate was purchased from Sigma (St. Louis, MO, USA).

Mouse model of thymic apoptosis. The BALB/c mice were randomly allocated into two groups: the experimental and the normal control groups. The mice in the experimental group were treated with an intraperitoneal injection of dexamethasone $(30 \mathrm{mg} / \mathrm{kg})$, while those in the normal control group were 
treated with physiological saline at the same dose. The thymus was removed $15 \mathrm{~h}$ post-injection when typical apoptotic morphology was observed (8). The mice were then divided into three groups for analysis using transmission electron microscopy, immunofluorescence and immunohistochemistry.

Preparation of frozen sections. Immediately following dissection, the thymic tissues were fixed with periodate-lysineparaformaldehyde fixative for $4 \mathrm{~h}$ at $4^{\circ} \mathrm{C}$. After washing with $0.01 \mathrm{M}$ phosphate-buffered saline (PBS; pH 7.4), the tissues were immersed in 5\% sucrose phosphate buffer for $1 \mathrm{~h}, 15 \%$ sucrose phosphate buffer for $2 \mathrm{~h}$ and finally in $30 \%$ sucrose phosphate buffer overnight at $4^{\circ} \mathrm{C}$. The tissues were embedded in optimal cutting temperature compound for $30 \mathrm{~min}$ and immersed in a mixture of acetone and dry ice.

Tissue preparation for transmission electron microscopy. The mouse thymic tissues were fixed in $2.5 \%$ glutaraldehyde through arterial perfusion. Post-fixation was performed with $1 \%$ osmium trioxide. The thymic tissues were dehydrated with acetone and then embedded in Epon 812. Thin sections $(0.5 \mu \mathrm{m})$ were observed under a light microscope to identify the location of positive cells in the tissues. Ultra-thin sections were observed under an H-600 transmission electron microscope.

Immunofluorescence assay. Frozen sections ( $8 \mu \mathrm{m}$ thick) were placed on poly-L-lysine-coated glass slides and dried in air. Following fixation with acetone, the sections were incubated in $0.25 \%$ Triton X-100 for 15 min. Regarding the F4/80 group, the sections were incubated with the anti-F4/80 mAb overnight at $4^{\circ} \mathrm{C}$. After washing with PBS, FITC-labeled goat anti-rat IgG was added and incubated for $1 \mathrm{~h}$ at room temperature. For Mac-2 staining, the sections were incubated with the anti-Mac-2 antibody overnight at $4^{\circ} \mathrm{C}$. After washing with PBS, biotin-SP-conjugated affinity purified donkey anti-rabbit IgG was added and incubated for $1 \mathrm{~h}$ at room temperature, washed again with PBS, and then ExtrAvidin-Cy3 was added and incubated for $1 \mathrm{~h}$ at room temperature. For the ED1 group, the sections were incubated with the anti-ED1 mAb overnight at $4^{\circ} \mathrm{C}$. After washing with PBS, the goat anti-rabbit IgG/RBITC secondary antibody was added and incubated for $1 \mathrm{~h}$ at room temperature.

Double staining was performed for the F4/80 + Mac-2 group, in which sections were incubated with the anti-F4/80 $\mathrm{mAb}$ overnight at $4^{\circ} \mathrm{C}$. The sections were washed with PBS and the FITC-labeled goat anti-rat IgG was added and incubated for $1 \mathrm{~h}$. They were then washed with PBS, blocked with $5 \%$ normal goat serum for $30 \mathrm{~min}$ prior to the addition of the anti-Mac-2 antibody and incubated for $1 \mathrm{~h}$. The sections were washed with PBS and the biotin-SP-conjugated donkey antirabbit $\mathrm{IgG}$ was added and incubated for $1 \mathrm{~h}$, washed with PBS, and finally ExtrAvidin-Cy3 was added and incubated for $1 \mathrm{~h}$. In the F4/80 + ED1 group, the sections were incubated with the anti-F4/80 $\mathrm{mAb}$ overnight at $4^{\circ} \mathrm{C}$. Following washing with PBS, the FITC-labeled goat anti-rat IgG was added and incubated for $1 \mathrm{~h}$, washed again with PBS and blocked with 5\% normal goat serum for $30 \mathrm{~min}$; the anti-ED1 mAb was added and incubated for $1 \mathrm{~h}$. The samples were then washed with PBS and the secondary goat anti-rabbit IgG/RBITC antibody was added and incubated for $1 \mathrm{~h}$. Sections from the normal control group were only incubated with the fluorescent-conjugated antibody. All the sections were observed under a fluorescence microscope.

Immunohistochemistry and ACP double staining. Frozen sections, treated with $5 \%$ normal goat serum for $15 \mathrm{~min}$, were incubated with the anti-F4/80, anti-Mac-2 and anti-ED1 mAbs. Following washing with PBS, the sections were incubated with the rabbit anti-rat IgG and the goat anti-rabbit IgG antibodies. The sections were washed with PBS and incubated with DAB solution. The reaction was terminated with deionized water and then incubated with ACP for $45 \mathrm{~min}$ at $37^{\circ} \mathrm{C}$. Counterstaining with methyl green was performed after the sections were washed with PBS. The sections were immediately immersed in 100\% alcohol and xylene, and mounted with India rubber. The prepared sections were observed under a light microscope.

\section{Results}

Morphology and distribution of distinct subpopulations of thymic macrophages. The majority of mouse thymic macrophages exhibit the shape of dendritic cells with well-developed cell processes extending into the narrow spaces around thymocytes. These types of macrophages were identified with anti-F4/80 and anti-Mac-2 antibodies (Fig. 1A-C), and they were distributed in the entire thymus (Fig. 1D). The second type of macrophage appeared as small oval cells, which notably lacked cell processes. These cells were strongly stained by anti-Mac-2; however, weakly stained by anti-F4/80 antibodies (Fig. 1E and F). Small oval macrophages were distributed in the thymic medulla and corticomedullary region (CMR; Fig. 1G). The third type of macrophage exhibited a flat shape and was distributed in the subcapsular region of the thymic cortex. These cells were F4/80+ but Mac-2 (Fig. 1H and I). The fourth type of macrophage exhibited an irregular shape and was distributed in the CMR. The number of these types of macrophage which exhibited ED1 ${ }^{-}$and F4/80 ${ }^{+}$staining was low (Fig. 1J-L). Fluorescent cells were not observed in the negative control group (data not shown).

Phagocytes of thymic macrophages. In the control group, the shape of thymocytes was normal, and the cell membrane and nucleus of thymocytes were integrated (Fig. 2A). By contrast, in the dexamethasone-injected mice, the membranes of phagocytes fused with lymphocytes (Fig. 2B). Additionally, numerous apoptotic bodies were observed in the phagocytes along with hyperdense grains and nuclear chromatin. Inclusion bodies surrounded by the membrane structure were also observed in the cytoplasm of phagocytes (Fig. 2C-F). Phagocytosis was observed in dendritic macrophages, which presented as swollen cells exhibiting strong fluorescent staining (Fig. 3).

Mouse thymic tissue assessment using double antibody and ACP staining. All of the four subpopulations of mouse thymic macrophages described above exhibited ACP activity. There were a large number of $\mathrm{F} 4 / 80^{+}$cells (Fig. 4A). Compared with the $\mathrm{F} 4 / 80^{+}$cells, there were fewer Mac- $2^{+}$cells stained positive for ACP (Fig. 4B). The ED1 ${ }^{+}$cells were mainly distributed in the CMR (Fig. 4C). $\mathrm{ACP}^{+}$cells were not observed in the 


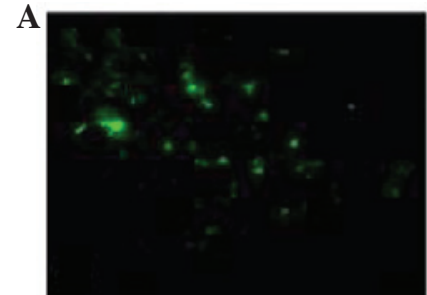

$\mathbf{E}$
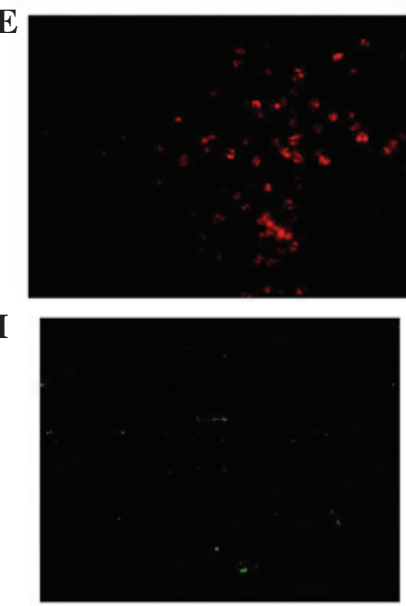

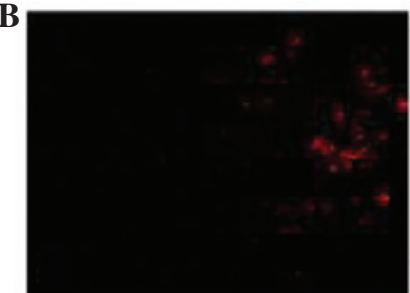

F

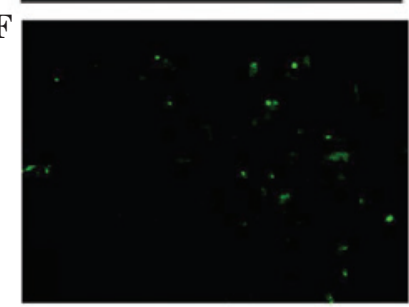

$\mathbf{J}$

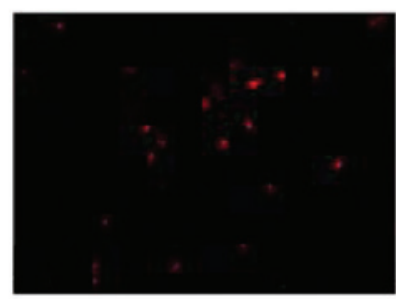

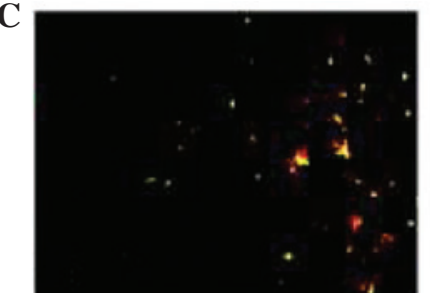
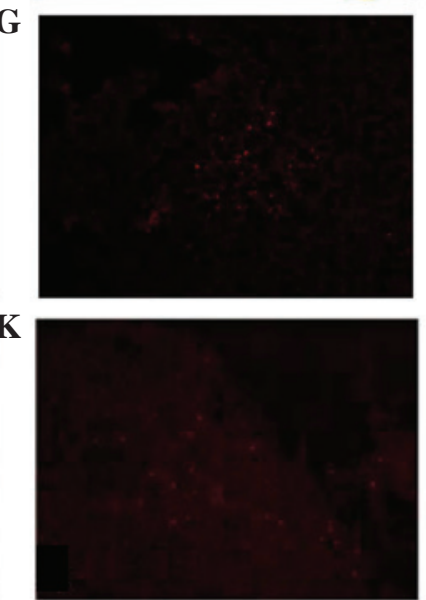
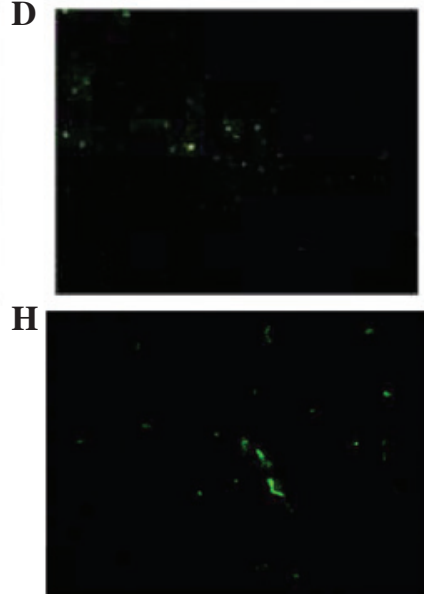

$\mathbf{L}$

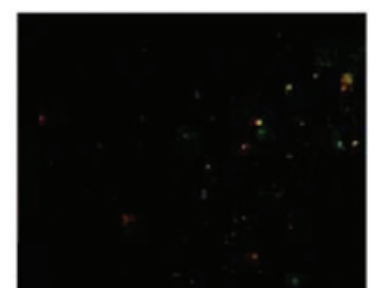

Figure 1. Morphology of the subpopulations of thymic macrophages in mice. (A-D) Dendritic macrophages. Frozen sections from mouse thymic tissues were immunoassayed with (A and D) anti-F4/80-FITC (green); (B) anti-Mac-2 (red) or (C) both antibodies. (A-C) Magnification, x400 and (D) x200. (E-G) Small oval macrophages. Frozen sections from mouse thymic tissues were immunoassayed with (E) anti-Mac-2 (red); (F) anti-F4/80-FITC, where they were observed to be distributed in the cortex (green) or (G) anti-F4/80-FITC antibodies, where they were observed to be distributed in the medulla. Magnification, $\mathrm{x} 400$. (H and I) Flat-shaped macrophages. Frozen sections from mouse thymic tissues were immunoassayed with anti-F4/80-FITC antibody. (H) Magnification, $\mathrm{x} 400$ and (I) x200. (J-L) ED1 macrophages. Frozen sections of mouse thymic tissues were immunostained with (J) anti-ED1 antibody (red); (K) ED1 distributed in the CMR or (L) anti-F4/80-FITC and anti-ED1 antibodies. (J) Magnification, x400 and (K and L) x200. CMR, corticomedullary region.

A

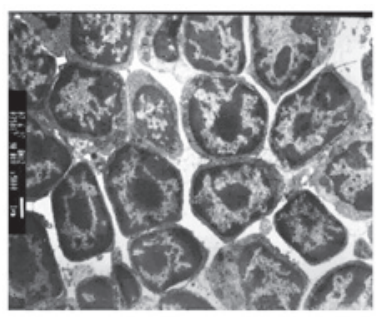

D

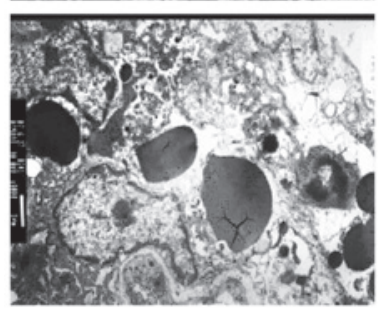

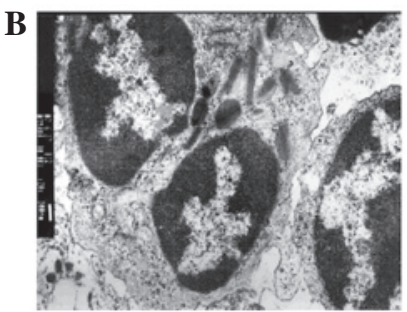

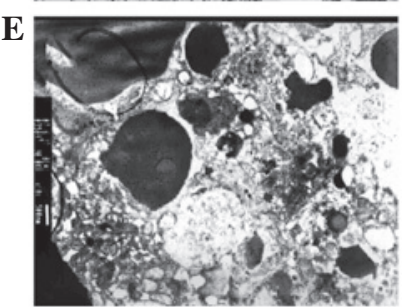

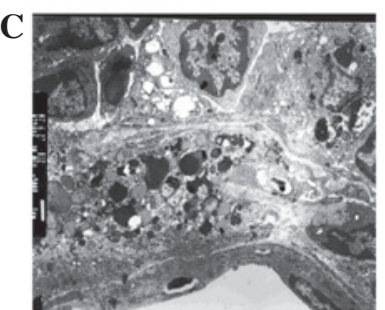

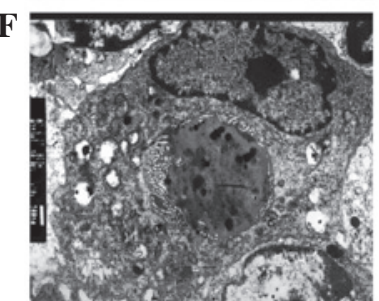

Figure 2. Phagocytes of thymic macrophages were observed by transmission electron microscopy. (A) The thymus was normal in mice of the control group. (B) In the dexamethasone-injected mice, the phagocyte membrane was fused with lymphocytes; however, pinocytosis was not observed. (C) Numerous apoptotic bodies; (D) hyperdense grains and (E) nuclear chromatin were also observed in the phagocytes of the dexamethasone-injected mice. (F) Inclusion bodies with membrane structures were observed in the cytoplasm of the phagocytes of the dexamethasone-injected mice. Scale bar, (A, C and D) $1 \mu \mathrm{m}$; (B) $200 \mathrm{~nm}$ and (E and F) $500 \mathrm{~nm}$.

negative control group (Fig. 4D). The subpopulations of mouse thymic macrophages are listed in Table I.

\section{Discussion}

In the present study, morphological and immunohistochemical analysis of macrophages in the mouse thymus was performed using anti-F4/80, anti-Mac-2 and anti-ED1 mAbs. The cell types of this organ were not adequately identified by staining the thymus with a single fluorescent antibody. Therefore, the application of double-antibody staining using fluorescent antibodies was required. Generally, the anti-ED1 mAb has been considered valuable in the identification of rat macrophages. However, whether mouse thymic macrophages are able to be identified using the anti-ED1 antibody still remains to be elucidated. In the present study, we used anti-ED1 mAb for the 
Table I. Characteristics of the subpopulations of mouse thymic macrophages.

\begin{tabular}{lcccc}
\hline & \multicolumn{4}{c}{ Cell subpopulation (shape) } \\
\cline { 2 - 5 } Characteristic & Dendritic & Round & Flat Irregular \\
\hline Phenotype & + & - & + & - \\
F4/80 & + & + & - & - \\
Mac-2 & - & - & - & + \\
ED1 & & & & \\
Distribution & ++ & +- & +- & + \\
Cortex & ++ & + & - & ++ \\
Corticomedullary region & + & + & - & +- \\
Medulla & ++ & - & ND & + \\
Phagocytosis & & + & & \\
\hline
\end{tabular}

+ , positive cell; -, negative cell; ++ , many positive cells; +- , few positive cells; ND, not determined.

identification of mouse thymic macrophages to investigate the subpopulations of these cells.

In the present study, all of the $\mathrm{F} 4 / 80^{+}, \mathrm{Mac}^{2} 2^{+}$and $\mathrm{ED} 1^{+}$ cells exhibited an ACP activity. These cells were mainly distributed in the cortex and the CMR. Compared with F4/80 ${ }^{+}$ and $\mathrm{EDI}^{+}$cells, Mac- $2^{+}$cells were fewer in number and smaller in size. The results indicate that the macrophages with positive ACP activity contained a number of phagosomes. The majority of thymic macrophages were large in size and possessed rich cell processes. These cells were designated as dendritic macrophages and were observed to be distributed throughout the thymic parenchyma, expressing Mac-2 and F4/80. These macrophages have been considered as phagocytes, as they may play a role in the phagocytosis of dying thymocytes $(9,10)$. Dexamethasone-induced apoptosis of thymic lymphocytes in mice was observed by electron microscopy. It was shown that a number of phagosomes containing ingested thymocytes at various stages of degradation were present in the thymic macrophages with well-developed cell processes $(11,12)$. Furthermore, a subtype of dendritic macrophages was observed in the CMR. However, it still remains unknown whether dendritic and interdigitating dendritic cells are part of the same group of thymic macrophages $(13,14)$.

Small round macrophages lacking cell processes were mainly distributed in the medulla and the CMR. These cells were stained positive for Mac-2 and negative for F4/80. However, in the cortex, there were some weakly stained F4/80 ${ }^{+}$ cells. These cells may be involved in the final stage of thymocyte differentiation $(8,15)$. Electron microscopy showed that these small oval macrophages exhibited limited phagocytic activity, indicating that they may constitute immature macrophages that recently entered the thymus via blood vessels running through the septa to the medulla and/or the CMR (13).

The third type of mouse thymic macrophages were slender- and flat-shaped cells, extending their processes along and underneath the capsule. These macrophages were low in quantity and were found to be distributed in the subcapsular region. They were stained positive with anti-F4/80 antibody; however, negative with anti-Mac-2 and anti-ED1 mAbs. This type of macrophage was considered as an independent subset of thymic macrophages, which were different from the dendritic and oval macrophages described above. Thymocytes are extensively divided at the subcapsular region of the thymus; therefore, these flat macrophages
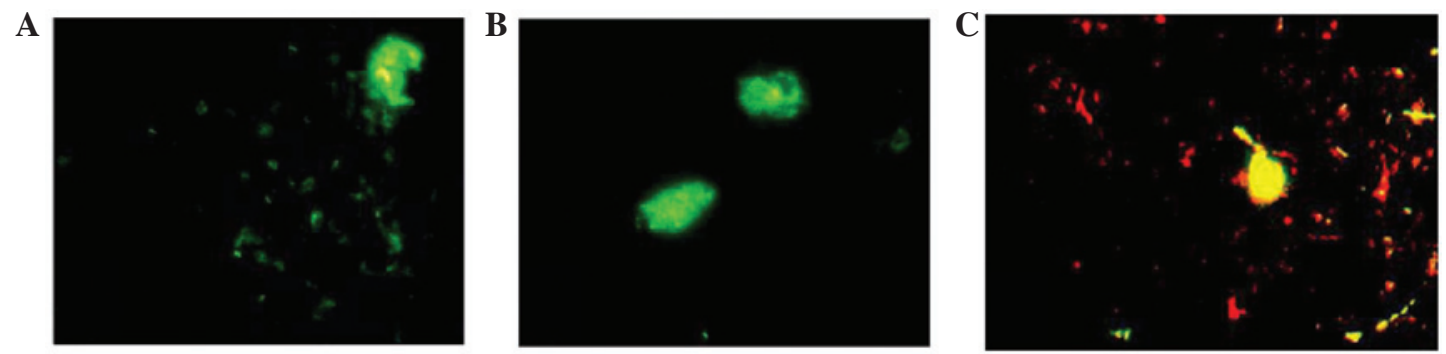

Figure 3. Macrophages. (A) Frozen sections of mouse thymic tissues were immunoassayed with the anti-F4/80-FITC antibody, where the cells were observed to be swollen. (B) Frozen sections of mouse thymic tissues were immunoassayed with anti-F4/80-FITC and anti-Mac-2 antibodies; the cells were hypertrophic dendrites. (C) The cells were also observed to be localized around the vessel. Magnification, $\mathrm{x} 400$.
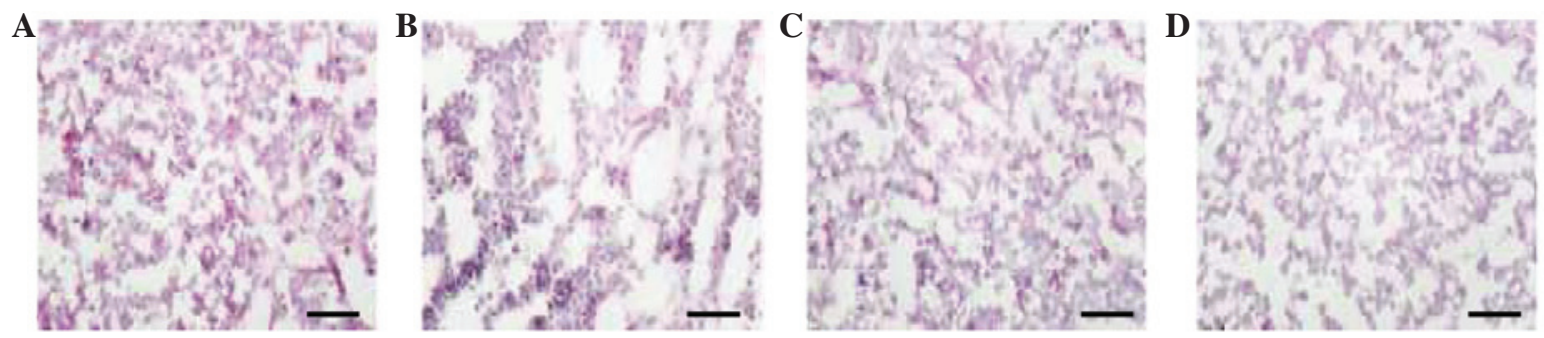

Figure 4. Mouse thymic tissues following double antibody and ACP staining. (A) Numerous F4/80- cells were also positive for ACP; (B) ED1 ${ }^{+}$cells with ACP grains were mainly distributed in the corticomedullary region; (C) Mac- $2^{+}$cells with $\mathrm{ACP}$ grains were low in number and lightly stained and (D) $\mathrm{ACP}^{+}$cells were not observed in the negative control group. Scale bar, $50 \mu \mathrm{m}$. ACP, acid phosphatase. 
may be important in thymocyte proliferation and selective differentiation (8).

The fourth type of thymic macrophage with an irregular form was observed to be mainly distributed in the CRM. They were diffused in the cortex and a small number of these cells were located in the medulla. Double-antibody staining showed that these cells were stained positive for F4/80 or $\mathrm{ED} 1$, while few cells were $\mathrm{F} 4 / 80^{+}$and $\mathrm{ED}^{+}$. According to the characteristic morphology and distribution of $\mathrm{ED}^{+}$cells, this type of macrophage was considered as an independent subset of thymic macrophages. The CMR macrophages that strongly express ED1 and F4/80 antigens have been suggested to be involved in the ingestion of dying thymocytes $(8,16)$.

In conclusion, the present study identified four subpopulations of mouse thymic macrophages and provided the platform to further investigate the function of thymic macrophages in the proliferation and differentiation of lymphocytes.

\section{Acknowledgements}

This study was supported by funding from the Education Bureau of Heilongjiang Province (no. 2011-318) and the Health Bureau of Heilongjiang Province (no. 12511585).

\section{References}

1. Castor A, Nilsson L, Astrand-Grundström I, Buitenhuis M, Ramirez C, Anderson K, Strömbeck B, Garwicz S, Békássy AN, Schmiegelow K, Lausen B, Hokland P, Lehmann S, Juliusson G, Johansson B and Jacobsen SE: Distinct patterns of hematopoietic stem cell involvement in acute lymphoblastic leukemia. Nat Med 11: 630-637, 2005.

2. Hung FM, Chuang YY, Lee CS, Chen YL, Yang JS, Lin JJ, Lu KW, Huang HY, Yu CC, Lu HF and Chung JG: Butylated hydroxyanisole affects immunomodulation and promotes macrophage phagocytosis in normal BALB/c mice. Mol Med Report 5: 683-687, 2012.
3. de Pooter RF, Cho SK, Carlyle JR and Zúñiga-Pflücker JC: In vitro generation of $\mathrm{T}$ lymphocytes from embryonic stem cell-derived prehematopoietic progenitors. Blood 102: 1649-1653, 2003.

4. Lee CK, Kim JK,Kim Y,Lee MK, Kim K, Kang JK, HofmeisterR, Durum SK and Han SS: Generation of macrophages from early T progenitors in vitro. J Immunol 166: 5964-5969, 2001.

5. Luo H, Hao Y, Tang B, Zeng D, Shi Y and Yu P: Mouse forestomach carcinoma cells immunosuppress macrophages through transforming growth factor- $\beta 1$. Mol Med Report 5: 988-992, 2012.

6. Naito M, Umeda S, Yamamoto T, Moriyama H, Umezu H, Hasegawa G, Usuda H, Shultz LD and Takahashi K: Development, differentiation, and phenotypic heterogeneity of murine tissue macrophages. J Leukoc Biol 59: 133-138, 1996.

7. Dijkstra CD, Dopp EA, Joling P and Kraal G: The heterogeneity of mononuclear phagocytes in lymphoid organs: distinct macrophage subpopulations in the rat recognized by monoclonal antibodies ED1, ED2 and ED3. Immunology 54: 589-599, 1985.

8. Soga H, Nakamura M, Yagi H, Kayaba S, Ishii T, Gotoh T and Itoh T: Heterogeneity of mouse thymic macrophages: I. Immunohistochemical analysis. Arch Histol Cytol 60: 53-63, 1997.

9. Jamieson CH, Ailles LE, Dylla SJ, Muijtjens M, Jones C, Zehnder JL, Gotlib J, Li K, Manz MG, Keating A, Sawyers CL and Weissman IL: Granulocyte-macrophage progenitors as candidate leukemic stem cells in blast-crisis CML. N Engl J Med 351: 657-667, 2004.

10. Perry SS, Pierce LJ, Slayton WB and Spangrude GJ: Characterization of thymic progenitors in adult mouse bone marrow. J Immunol 170: 1877-1886, 2003.

11. Akashi K, Richie LI, Miyamoto T, Carr WH and Weissman IL: B lymphopoiesis in the thymus. J Immunol 164: 5221-5226, 2000.

12. Foss DL, Donskoy E and Goldschneider I: The importation of hematogenous precursors by the thymus is a gated phenomenon in normal adult mice. J Exp Med 193: 365-374, 2001.

13. Hashimoto S, Suzuki T, Dong HY, Yamazaki N and Matsushima K: Serial analysis of gene expression in human monocytes and macrophages. Blood 94: 837-844, 1999.

14. Laskin DL, Weinberger B and Laskin JD: Functional heterogeneity in liver and lung macrophages. J Leukoc Biol 70: 163-170, 2001.

15. Hume DA, Ross IL, Himes SR, Sasmono RT, Wells CA and Ravasi T: The mononuclear phagocyte system revisited. J Leukoc Biol 72: 621-627, 2002.

16. Huitinga I, Bauer J, Strijbos PJ, Rothwell NJ, Dijkstra CD and Tilders FJ: Effect of annexin-1 on experimental autoimmune encephalomyelitis (EAE) in the rat. Clin Exp Immunol 111: 198-204, 1998. 